\title{
Congenital multiple eventrations of the right diaphragm in adulthood
}

\author{
Liang Wu, MD, ${ }^{\mathrm{a}}$ Jinyun Shi, MD, ${ }^{\mathrm{b}}$ Qiankun Chen, $\mathrm{MD},{ }^{\mathrm{a}}$ and Gening Jiang, $\mathrm{MD}^{\mathrm{a}}$
}

Eventration of the diaphragm is an abnormal elevation of part or all of the diaphragm as a result of paralysis, aplasia, or atrophy of varying degree of muscle fibers. ${ }^{1}$ Unlike diaphragmatic hernia, the diaphragm itself is intact, and there is no communication between abdominal and thoracic cavities. It is most often detected incidentally on radiographs and is frequently asymptomatic. Here we present the case of a 57-year-old woman with asymptomatic congenital multiple eventrations of the right diaphragm.

\section{CLINICAL SUMMARY}

A 57-year-old woman was referred to our hospital for a mass over the right thorax found through a regular screening. The plain radiograph (Figure 1, A) showed a round density lying above the right diaphragm. Because of the suspicion of a thoracic tumor, she was transferred to our department for further diagnostic testing. Results of general physical examination were normal. She could recall no major surgical or traumatic history.

Computed tomography (Figure 1, B) revealed an $8.5 \times 7.7-\mathrm{cm}$ homogeneous mass in the right thoracic cavity. A bronchoscopy showed nothing of abnormal appearance. We decided to perform an exploratory thoracotomy

From the Department of Thoracic Surgery, ${ }^{\text {a }}$ Shanghai Pulmonary Hospital, Shanghai,

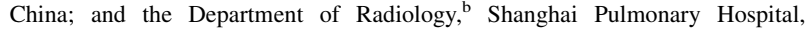
Shanghai, China.

Disclosures: Authors have nothing to disclose with regard to commercial support.

Received for publication Aug 12, 2013; accepted for publication Dec 31, 2013; available ahead of print Feb 9, 2014

Address for reprints: Gening Jiang, MD, Department of Thoracic Surgery, Shanghai Pulmonary Hospital, Tongji University School of Medicine, 507 Zheng Min Rd,

Shanghai 200433, PR China (E-mail: awen.he@yahoo.com).

J Thorac Cardiovasc Surg 2014;148:735-6

$0022-5223 / \$ 36.00$

Copyright $(2014$ by The American Association for Thoracic Surgery

http://dx.doi.org/10.1016/j.jtcvs.2013.12.053 to identify the nature of the mass. After adhesiolysis of the lung from the pleura and diaphragm, we could look straight into the right thoracic cavity. The diaphragm was found to be intact but weak and thin, with 1 major hump lying posteriorly and 2 minor ones lying anteriorly. Intraoperative biopsy revealed normal liver tissue under the bulging diaphragm. After the operation, we therefore did sagittal (Figure 2, A), coronal, and 3-dimensional (Figure 2,B) reconstructions of the liver, which confirmed the diagnosis. The patient had an uneventful postoperative course.

\section{DISCUSSION}

The first case of eventration of the diaphragm was described by Jean Louis Petit in 1774. It is generally regarded as a condition in which the left or the right cupola of the diaphragm has ascended abnormally high into the thorax. It can be congenital or acquired. Congenital eventration is the result of incomplete muscularization of the membranous diaphragm during fetal life, whereas the acquired form may be secondary to trauma, inflammation, or local neoplastic invasion of the phrenic nerve. The eventration may be complete or partial. A complete eventration of the diaphragm is more common on the left side, whereas partial eventration is more common on the right. The most common site of partial eventration is the anteromedial aspect of the right diaphragm. Congenital multiple eventrations of the right diaphragm in an elderly woman, as seen in our case, is very rare. To our knowledge, no similar cases have been reported in the literature before. Although diaphragmatic eventration is frequently asymptomatic, progressive enlargement of the eventration may lead to dyspepsia and respiratory and cardiac symptoms.

The eventration is often detected initially through chest radiography; however, it is difficult to distinguish an
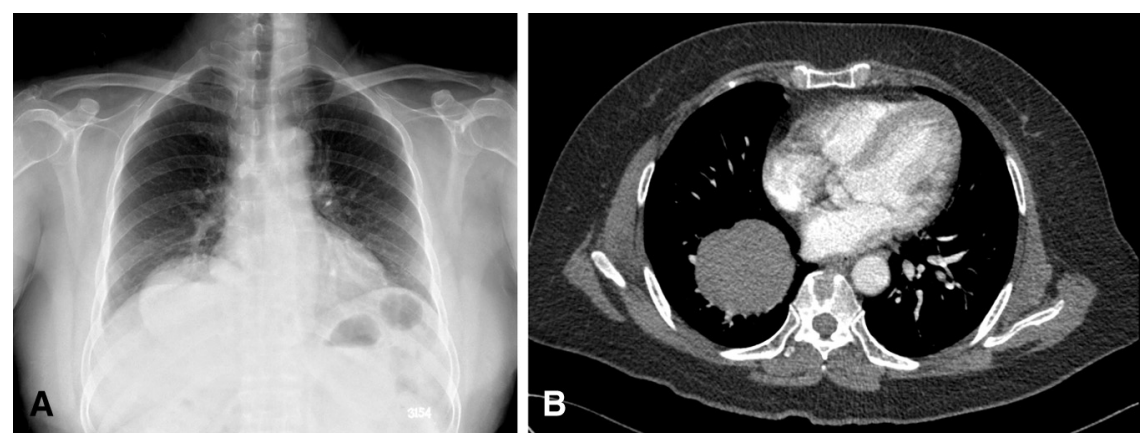

FIGURE 1. A, Chest radiography showing a round density lying above the right diaphragm. B, Computed tomographic scan demonstrating a homogeneous mass in the right thoracic cavity. 

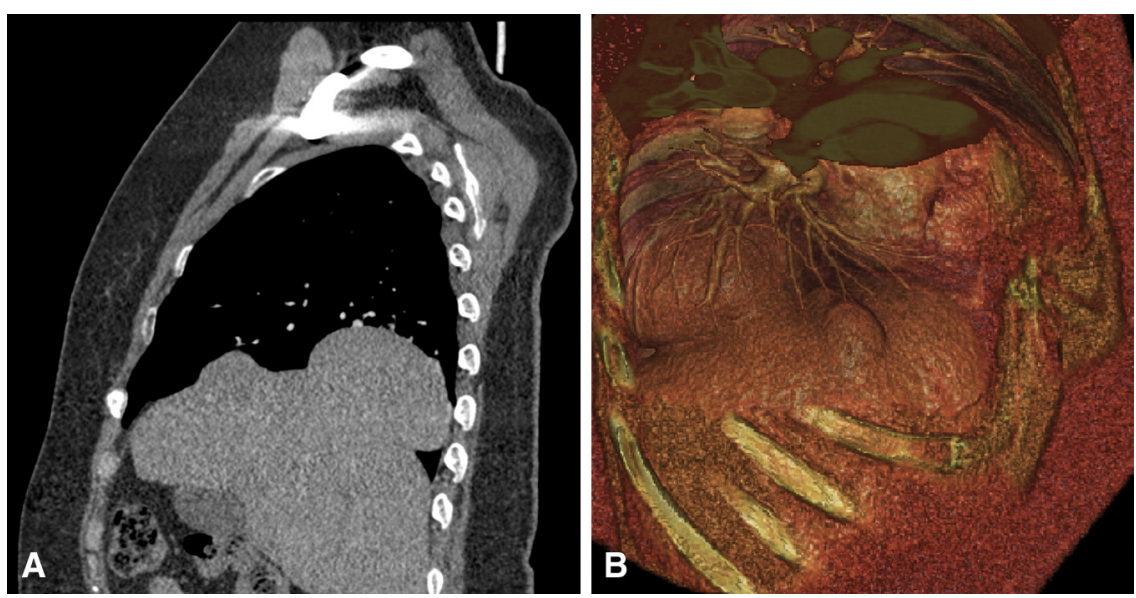

FIGURE 2. A, Sagittal reconstruction of the liver showing multiple eventrations of the right diaphragm. B, Three-dimensional reconstruction of the liver showing 1 major eventration lying posteriorly and 2 minor ones lying anteriorly.

eventration from the other diaphragmatic or mediastinal lesions on the radiographs. The diagnosis may be more difficult to make in case of partial eventration on the right diaphragm, because the elevated dome is often filled by protrusion of the liver mimicking a tumor. In this condition, the eventration is always discovered during operation. Other imaging modalities, such as fluoroscopy, liver scan, ultrasonography, computed tomography, and magnetic resonance imaging, may be performed as adjuvant techniques in cases in which the diagnosis still unclear. ${ }^{2}$ Multiplanar reconstruction images may be useful in evaluation of diaphragm integrity and eventrated abdominal content.

It is well established that surgical treatment is indicated for patients with symptoms that can be related to this pathologic condition. Surgery may be a lifesaving measure in infants and children with dyspnea. The accepted surgical procedure for diaphragmatic eventration is plication of the diaphragm with thoracotomy or videoassisted thoracic surgery. ${ }^{3}$ Some authors recommend enforcing the repair with a synthetic mesh. ${ }^{4}$ The results of surgical treatment are usually satisfying, with low morbidity and mortality. ${ }^{5}$

In conclusion, congenital eventration of the right diaphragm in an adult is a rare entity. Getting to know this entity is important to the surgeons, because it can be misleading and mistaken for more serious diseases, which may lead to unnecessary surgery.

\section{References}

1. Thomas TV. Congenital eventration of diaphragm. Ann Thorac Surg. 1970;10: 180-92.

2. Gierada DS, Slone RM, Fleishman MJ. Imaging evaluation of the diaphragm. Chest Surg Clin N Am. 1998;8:237-80.

3. Groth SS, Rueth NM, Kast T, D'Cunha J, Kelly RF, Maddaus MA, et al. Laparoscopic diaphragmatic plication for diaphragmatic paralysis and eventration: an objective evaluation of short-term and midterm results. J Thorac Cardiovasc Surg. 2010;139:1452-6.

4. Balci AE, Ozyurtkan MO. Clinical and surgical specifications of adult unilateral diaphragmatic eventration according to their aetiology in 28 patients. Importance of using diaphragmatic patch and minimal thoracotomy incision. Eur J Cardiothorac Surg. 2010;37:606-12.

5. Leo F, Venissac N, Morales F, Rodriguez A, Mouroux J. Plication for diaphragmatic eventration: a simple technique, not a simple problem [letter]. Chest. 2004;125:1170; author reply 1170-1. 